\title{
Effect of rest interval on cardiovascular responses after resistance exercise ${ }^{1}$
}

\author{
Aluísio Henrique Rodrigues de Andrade Lima ${ }^{1}$ \\ Cláudia Lúcia de Moraes Forjaz ${ }^{2}$ \\ Gleyson Queiroz de Moraes Silva ${ }^{1}$ \\ Ana Paula Andrade Lima ${ }^{1}$ \\ Ozéas Lima Lins Filho ${ }^{1}$ \\ Crivaldo Gomes Cardoso Júnior ${ }^{3}$ \\ Raphael Mendes Ritti-Dias \\ ${ }^{1}$ School of Physical Education, University of Pernambuco, Recife, PE, Brazil \\ ${ }^{2}$ School of Physical Education and Sport, University of São Paulo, São Paulo, SP, Brazil \\ ${ }^{3}$ Center of Physical Education and Sport, State University of Londrina, Londrina, PR, Brazil
}

\begin{abstract}
Objective: To analyze the acute effect of rest interval length on cardiovascular response after resistance exercise. Methods: Twenty young eutrophic men $\left(23.9 \pm 0.7\right.$ years;23.8 $\left.\pm 0.5 \mathrm{~kg} / \mathrm{m}^{2}\right)$ performed two experimental sessions in a random order: resistance exercise with a 30 -second (130) and with a 90second (190) rest interval between sets. Both sessions included five exercises with $50 \%$ of the one-repetition maximum. Before and 24 hours after the experimental sessions, systolic blood pressure (SBP), diastolic blood pressure (DBP), heart rate (HR), and rate-pressure product (RPP) were obtained. Results: The SBP, DBP and RPP responses were similar between the I30 and 190 sessions $(p>0.05)$, while the HR after I30 was significantly higher than after $190(p<0.01)$ for the first hour after exercise. The cardiovascular responses during the first 24 hours were similar between both sessions ( $p>0.05)$. Conclusion: Different recovery intervals did not promote post-exercise hypotension, however, a short rest interval increases heart rate for 1 hour after exercise. In addition, within 24 hours of the responses were similar between groups.
\end{abstract}

Key words: Strength training. Post-exercise hypotension. Rest interval. Blood pressure. Cardiovascular responses.

\section{Efeito do intervalo de recuperação nas respostas cardiovasculares pós-exercício de força}

Resumo: Objetivo: Analisar o efeito agudo do intervalo de recuperação na resposta cardiovascular após o exercício de força. Métodos: Vinte homens jovens eutróficos $\left(23,9 \pm 0,7\right.$ anos; $\left.23,8 \pm 0,5 \mathrm{~kg} / \mathrm{m}^{2}\right)$ realizaram duas sessões experimentais em ordem aleatória: exercício de força com 30 segundos (I30) e com 90 segundos (190) de intervalo de recuperação entre séries. As sessões incluíram cinco exercícios com 50\% de uma repetição máxima. Antes e 24 horas após as sessões experimentais, pressão arterial sistólica (PAS), pressão arterial diastólica (PAD), frequência cardíaca $(F C)$ e duplo produto (DP) foram obtidos. Resultados: A resposta da PAS, PAD e DP foi similar entre os grupos $(p>0,05)$, enquanto a FC após a I30 foi significantemente maior que a $190 \quad(p<0,01)$ na primeira hora pós-exercício. As respostas cardiovasculares durante as 24 horas foram similares entre as sessões ( $p>0,05)$. Conclusão: Diferentes intervalos de recuperação não promoveram hipotensão pós-exercício, entretanto, um curto intervalo de recuperação aumentou a FC por uma hora pós-exercício. Além disso, nas 24 horas seguintes as respostas foram similares entre os grupos.

Palavras-chave: Exercício de força. Hipotensão pós-exercício. Intervalo de recuperação. Pressão arterial. Respostas cardiovasculares.

\section{Introduction}

After a single bout of resistance exercise, blood pressure (BP) decreases to levels lower than in the pre-exercise period, which is known as post-exercise hypotension (FORJAZ et al., 2004; FORJAZ et al., 1998; FORJAZ et al., 2000). This

\footnotetext{
1 The resume of this study was presented at XXXIII Congresso da Sociedade de Cardiologia do Estado de São Paulo (June 2011, São Paulo, Brazil)
}

phenomenon occurs in normotensive and hypertensive subjects and although it has clinical importance for the latter (PESCATELLO et al., 2004), it has been extensively studied in the former (CASTINHEIRAS-NETO et al., 2010; MENÊSES et al., 2011; REZK et al., 2006) to understand its behavior in a population with low cardiovascular risk and without pathological influences. 
Several studies have indicated that the magnitude of post-exercise hypotension is affected by the resistance exercise method. Current data suggest that post-exercise hypotension is greater after multiple sets of resistance exercise for the major muscle groups (MEDIANO et al., 2005; POLITO; FARINATTI, 2009). Despite this evidence, the impact of other resistance exercise variables on post-exercise cardiovascular responses remains unclear.

Inter-set rest interval is an important variable in resistance training because it affects both acute performance (KRAEMER; RATAMESS, 2005; RATAMESS et al., 2007) and chronic adaptations promoted by training (AMERICAN COLLEGE OF SPORTS MEDICINE, 2009; PINCIVERO et al., 1997). However, whether this variable influences post-exercise cardiovascular response is poorly known. To date, only two studies have analyzed the effect of the inter-set rest interval on cardiovascular response after resistance exercise. In both studies, the cardiovascular response after resistance exercise was independent of the rest interval adopted (DE SALLES et al., 2010; VELOSO et al., 2010). However, neither employed rest intervals shorter than 1 minute, which is known to promote greater metabolite accumulation (RATAMESS et al., 2007; TAKARADA; ISHII, 2002). Thereby, resistance exercise with a shorter rest interval might promote greater vasodilatation, leading to a greater postexercise hypotension (MACDONALD, 2002).

Low-intensity resistance exercise (approximately $50 \%$ of $1 \mathrm{RM}$ ) and long duration of inter-set intervals ( 1 to $2 \mathrm{~min}$ ) have been recommended for hypertensive patients (WILLIAMS et al., 2007). However, whether resistance exercise prescribed at this intensity and shorter rest intervals potentiate the post-exercíse hypotension remains unknown. Therefore, the purpose of this study was to analyze the effect of rest interval length on cardiovascular response after resistance exercise of low-intensity. The hypotheses are that systolic and diastolic BP decrease after resistance exercise performed with 30 and 90 seconds of rest interval; however, greater responses occur after the session with a shorter inter-set rest interval.

\section{Subjects}

\section{Methods}

Twenty male recreational lifters aged between 18-30 years were recruited from the university and local communities. The participants were submitted to a cardiovascular screening based on the American College of Sports Medicine guidelines (AMERICAN COLLEGE OF SPORTS MEDICINE, 2007). Participants who indicated the presence of diseases or limiting factors for physical activity practice, such as orthopedic or cardiovascular problems, were not included in this study. Anthropometric and BP measurements were also performed, and only individuals who had a systolic BP lower than $130 \mathrm{mmHg}$ and a diastolic BP lower than $85 \mathrm{mmHg}$ at rest were included. In addition, participants were included if they had been practicing resistance exercise for at least six months before the study. The participants' characteristics are presented in table 1.

Table 1. Baseline characteristics of the sample

\begin{tabular}{lc}
\hline & Mean \pm standard error \\
\hline Age $(\mathrm{y})$ & $23.9 \pm 0.7$ \\
Body mass $(\mathrm{kg})$ & $73.7 \pm 3.7$ \\
Height $(\mathrm{m})$ & $1.76 \pm 0.04$ \\
Body mass index $\left(\mathrm{kg} / \mathrm{m}^{2}\right)$ & $23.8 \pm 0.5$ \\
Systolic Blood Pressure $(\mathrm{mmHg})$ & $117 \pm 2$ \\
Diastolic Blood Pressure $(\mathrm{mmHg})$ & $77 \pm 1$ \\
1-RM Bench press $(\mathrm{kg})$ & $83.2 \pm 3.0$ \\
1-RM Knee extension $(\mathrm{kg})$ & $77.7 \pm 2.7$ \\
1-RM Seated row $(\mathrm{kg})$ & $81.0 \pm 2.7$ \\
1-RM Knee curl $(\mathrm{kg})$ & $41.3 \pm 0.7$ \\
1-RM Frontal raise $(\mathrm{kg})$ & $24.8 \pm 3.0$ \\
\hline
\end{tabular}

1-RM - 1 repetition maximum test

All of the participants were informed about the procedures of the study and provided their written consent. This study was approved by the Institutional Review Board of the University of Pernambuco.

\section{Experimental design}

Prior to the experimental sessions, each subject underwent one adaptation session to the resistance exercises. In this session, the participants performed 3 sets of 12 repetitions on 
bench press, knee extension, seated row, knee curl, and frontal raise exercises. All of the exercises were performed without a load.

Two days after the adaptation session, the participants performed a one repetition maximal (1-RM) test (CLARKE, 1973). The test began with a warm up with 12 repetitions using $50 \%$ of the estimated load for the first attempt. Three attempts were performed until the 1-RM load was identified. A 2-minute rest interval was adopted between the attempts and the exercises. The 1$\mathrm{RM}$ tests were repeated for all exercises in a different session with a minimum interval of 48 hours. The purpose of this procedure was to guarantee the maximal accuracy of the 1-RM load, as suggested previously (SOARES et al., 2009). The highest load identified between both sessions was used to calculate the exercise intensity in the experimental sessions.

Two days after the 1-RM test, the participants started the experimental sessions: resistance exercise with a 30-second inter-set rest interval (I30) or resistance exercise with a 90-second inter-set rest interval (190). The session order (I30 or 190) was defined by simple randomization. The interval between experimental sessions was 7 days, and during this period the participants were instructed not to perform any resistance exercise.

The sessions were performed in the afternoon starting at $2 \mathrm{pm}$. The participants were instructed to eat a light meal two hours before the experimental session, not to perform any physical exercises the day before, to avoid alcoholic drinks for 48 hours prior, and not to drink caffeinated beverages for 12 hours prior to the experimental sessions.

At the beginning of each experimental session, the participants remained seated for 20 minutes in the laboratory. During this period, the systolic BP, diastolic BP, heart rate, and rate-pressure product were measured four times using an ambulatory blood pressure monitor (Dinamapa, Cardios, Brazil). After these measurements, the participants went to the resistance exercise room to perform the experimental intervention (I30 or 190).

Both sessions were composed of the 5 aforementioned resistance exercises performed in three sets of 10 repetitions at $50 \%$ of the $1-\mathrm{RM}$. In the 130 session, the inter-set rest interval was 30 seconds, and in the 190 session, the inter-set rest interval was 90 seconds.

After the exercises, the participants returned to the laboratory, and the ambulatory BP monitor was attached again. Then, the participants were allowed to continue their daily activities. The monitor was programmed to perform measurements every 15 minutes for 24 hours after the experimental session. Before each experimental session, the ambulatory blood pressure monitor calibration was checked against a mercury column. An appropriate cuff size was used for each patient's arm.

The ambulatory BP monitoring data were downloaded to a computer for data analysis. The systolic BP, diastolic BP, heart rate, and ratepressure product data obtained were averaged per hour to obtain the hour-to-hour cardiovascular response. These variables were also averaged over three periods: 24 hours, awake, and asleep. The nocturnal BP and heart rate fall were calculated in absolute values (mean awake mean asleep blood pressure). The morning surge was defined as the difference between the last 2 hours of sleep and the first two hours after awakening. Furthermore, an analysis was performed during the hours that the individuals remained awake ( 6 hours) after the experimental protocol.

\section{Statistical Analyses}

The sample size necessary to detect a difference of $6.0 \mathrm{mmHg}$ in BP was calculated to be 16 participants in each condition, considering a standard deviation of $2.5 \mathrm{mmHg}$, a power of $80 \%$, and an alpha error of $5 \%$.

The normality and homogeneity of the data were confirmed by the Shapiro Wilk and Levene tests, respectively. The pre-intervention data in both experimental sessions were compared by paired Student's $t$ test. The systolic BP, diastolic $\mathrm{BP}$, heart rate, and rate-pressure product were compared between sessions using two way ANOVA (rest interval $x$ period) for repeated measures. A post-hoc Newman-Keuls test was employed to probe for significant main effects and interactions. The cardiovascular responses after the sessions during the next 24 hours, awake and asleep periods, nocturnal fall, and morning surge were compared by paired Student's $t$ test. A value of $p \leq 0.05$ was accepted as significant. The data are presented as the means and standard error. 


\section{Results}

Eleven participants started with the 130 session, and 9 participants started with the 190 session. At pre-intervention, the systolic BP $(117 \pm$ 2 vs. $115 \pm 1 \mathrm{mmHg} ; \mathrm{p}=0.32)$, diastolic $\mathrm{BP}(66 \pm 2$ vs. $65 \pm 1 \mathrm{mmHg} ; \mathrm{p}=0.49)$, heart rate $(69 \pm 2$ vs. $69 \pm 2$ bpm; $p=0.22$ ), and rate-pressure product ( $8081 \pm 286$ vs. $7976 \pm 260 ; p=0.66$ ) were similar between the 130 and 190 sessions, respectively.

The cardiovascular responses during the first 6 hours after the intervention are presented in figure 1. In comparison with the pre-intervention values, systolic BP did not change after either session $(p>0.05)$, while diastolic BP increased similarly after both sessions from the third until the sixth hour of the recovery period $(p<0.01)$. As postexercise hypotension is usually observed in the first hour after the exercise, a complementary analysis was performed comparing blood pressure measured pre-exercise and values measured at 15,30 , and $45 \mathrm{~min}$ of recovery. Neither systolic nor diastolic blood pressure changed in comparison with pre-exercise levels in either of the sessions.
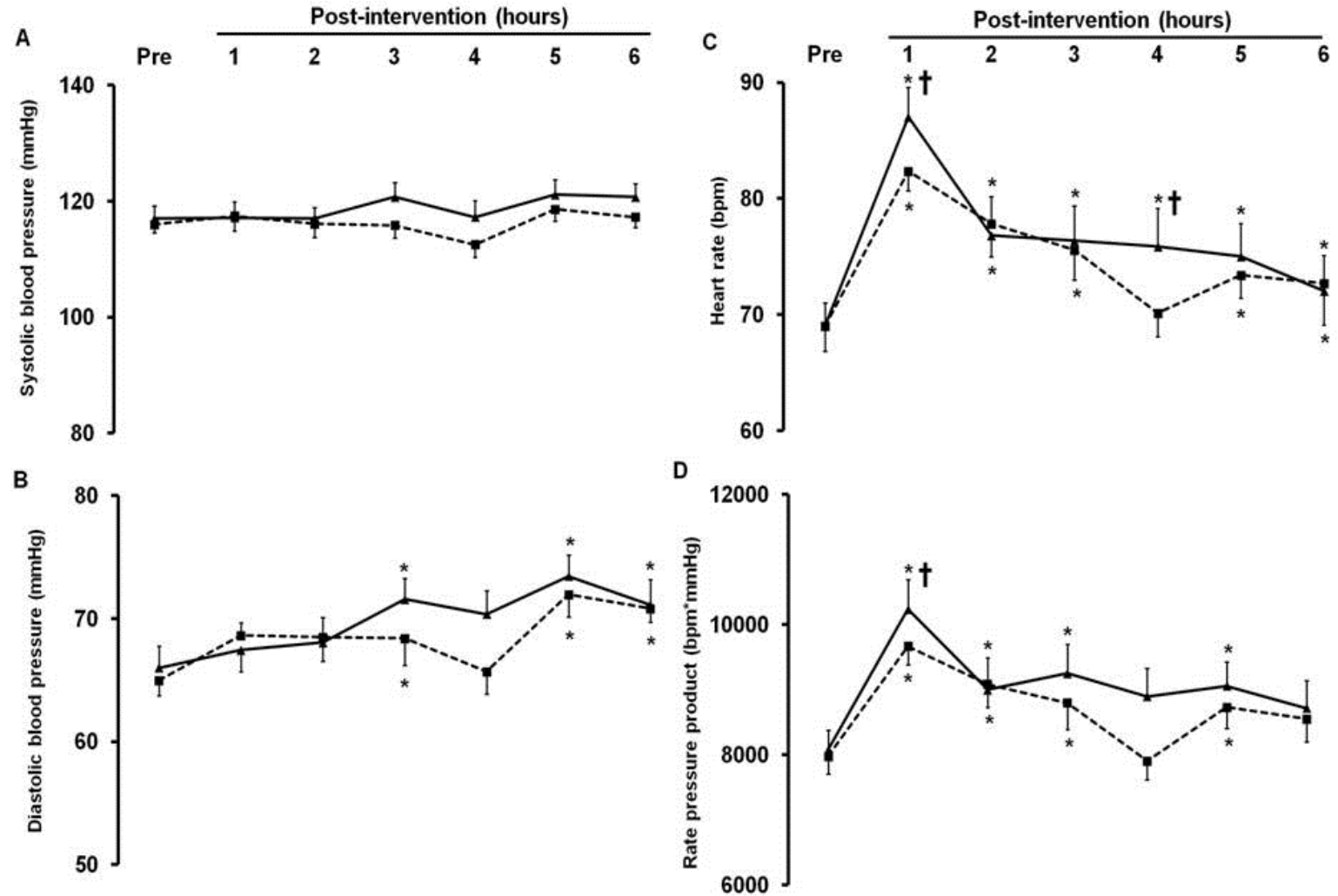

Figure 1. Systolic blood pressure (panel A), diastolic blood pressure (panel B), heart rate (panel C) and ratepressure product (panel D) pre- and post- intervention for resistence exercise sessions performed with 30 seconds (filled line) and 90 seconds (dashed line) rest intervals * Significantly different from pre-values $(p<0.05)$; †Significantly different from $190(p<0.05)$.

In comparison with the pre-intervention values, heart rate increased after both sessions from the first until the sixth hour of the recovery period $(p<0.01)$; however, the increases at the first and fourth hours after 130 were greater than after 190 $(p<0.01)$. In comparison with the pre-intervention values, rate-pressure product increased after both sessions at the first, second, third, fifth, and sixth hours of the recovery period $(p<0.01)$, however, the increases at the first hour after 130 were greater than after $190(p<0.01)$.

The cardiovascular responses during the 24 hour period after the two sessions are presented in table 2. The 24-hour, awake, asleep, nocturnal fall, and morning surge values of systolic BP, diastolic $\mathrm{BP}$, heart rate, and rate-pressure product were similar between the 130 and 190 sessions $(p>0.05)$. 
Table 2. Ambulatory responses after resistance exercise performed with 30 seconds of rest interval (I30) and 90 seconds of rest interval (190).

\begin{tabular}{lccc}
\hline & 130 & 190 & $p$ \\
\hline Systolic blood pressure (mmHg) & & & \\
24 hours & $113 \pm 2$ & $112 \pm 1$ & 0.360 \\
Awake perid & $118 \pm 2$ & $117 \pm 1$ & 0.108 \\
Asleep period & $104 \pm 2$ & $102 \pm 1$ & 0.335 \\
Diastolic blood pressure (mmHg) & & & \\
24 hours & $66 \pm 1$ & $66 \pm 1$ & 0.970 \\
Awake period & $70 \pm 1$ & $70 \pm 1$ & 0.675 \\
Asleep period & $58 \pm 1$ & $57 \pm 1$ & 0.286 \\
Heart rate (bpm) & & & 0.646 \\
24 hours & $67 \pm 2$ & $68 \pm 2$ & 0.666 \\
Awake period & $74 \pm 2$ & $74 \pm 2$ & 0.448 \\
Asleep period & $55 \pm 2$ & $55 \pm 2$ & 0.904 \\
Rate pressure product (bpm.mmHg) & & & 0.426 \\
24 hours & $7571 \pm 249$ & $7616 \pm 274$ & 0.772 \\
Awake period & $8732 \pm 304$ & $7488 \pm 298$ & 0.861 \\
Asleep period & $5720 \pm 247$ & $5610 \pm 224$ & 0.604 \\
Nocturnal blood pressure fall(mmHg) & & & \\
Systolic blood pressure & $-12 \pm 7$ & $-12 \pm 5$ & 0.455 \\
Diastolic blood pressure & $-16 \pm 7$ & $-17 \pm 7$ & 0.525 \\
Morning surge (mmHg) & & & \\
Systolic blood pressure & & $9 \pm \pm$ & \\
Diastolic blood pressure & $4 \pm 2$ & & \\
\hline Values are mean \pm standard eror & & & \\
\hline
\end{tabular}

Values are mean \pm standard error

\section{Discussion}

The main findings of this study were the following: a) after resistance exercise with 30 or $90 \mathrm{sec}$ of rest interval between sets, systolic BP did not change while diastolic BP, heart rate, and rate pressure product increased in comparison with pre-exercise levels; $b$ ) at the first hour after resistance exercise, heart rate and rate pressure product were higher for the 130 session than the 190 session; c) systolic BP, diastolic BP, heart rate, and rate-pressure product values measured during 24-hour, awake, and asleep periods, as well as the nocturnal fall and morning surge after exercise were similar between the 130 and 190 sessions.

In the present study, systolic BP did not decrease in comparison with pre-exercise levels after the resistance exercise. However, decreases in systolic BP have been frequently described after resistance exercise in normotensive subjects (POLITO; FARINATTI, 2009; REZK et al., 2006; SIMAO et al., 2005). Several factors might explain this controversy. This might occur due to different recovery methods adopted in the studies. While the participants in previous studies remained seated in the laboratory during recovery, in the current study participants were immediately released to their daily activities, which might have blunted the decrease in blood pressure. Queiroz et al (2009) have showed that in normotensive subjects laboratory post-exercise hypotension is not sustained during daily activities. It is possible that daily walking activities increased sympathetic activity, mitigating the post-exercise reduction in blood pressure, which might be further investigated. It is worth highlighting, however, that the protocol used in the current study presents greater external validity since in practice the participants are released for their daily activities immediately after the end of the exercise session. Another explanation for the difference in results may be the fact that previous studies employed mainly multi-join exercises that activates large muscle mass, while the present study employed some mono-join exercises. It has been proposed that post-exercise hypotension is greater after resistance exercise involving greater muscle groups (MEDIANO et al., 2005; POLITO; FARINATTI, 2009). Finally, different from previous studies, in the present study a control session without exercise was not performed. Some previous studies (PESCATELLO et al., 2003; WALLACE et al., 1999) have measured 
ambulatory BP before and after a control session and have observed that ambulatory systolic BP increases in comparison with values measured in the laboratory before the control intervention. Thus, even not decreasing BP in comparison with pre-exercise, the exercise session might have attenuated the increase in systolic BP that would have occurred in a control situation.

Previous studies observed similar
cardiovascular responses after resistance exercise with rest intervals between 1 and 3 minutes (DE SALLES et al., 2010; VELOSO et al., 2010). Because some studies have suggested that metabolite-induced vasodilation might affect the post-exercise hypotension mediated by nitric oxide (LIZARDO et al., 2008), in the current study we expected that a very short rest interval $(30 \mathrm{sec})$ could potentiate post-exercise hypotension. However, the results indicated that systolic BP responses were similar between the rest intervals. Although the mechanism underlying this effect was not analyzed in this study, it is possible that the intensity employed in the current study $(50 \%$ of the 1-RM) was not sufficient to promote metabolite accumulation, which limited the post-exercise hypotension. In fact, low intensity resistance exercises have been associated with low metabolic accumulation (LAGALLY et al., 2002) due to a smaller decrease in muscle blood flow, fiber recruitment, and shear stress, which are known to be important factors for metabolite accumulation.

In the current study, diastolic BP increased similarly between groups until 3 hours after the sessions, which differ from previous studies (POLITO; FARINATTI, 2009; REZK et al., 2006; VELOSO et al., 2010) that observed decreases after the experimental protocols with 45 and 90 seconds of rest interval. However, these studies evaluated BP in the laboratory and for a short time after exercise, while the present study observed BP during ambulatory conditions. In fact, in the present study, pre-exercise BP was measured after a 20-min rest, while post-exercise BP was measured while the subjects were doing daily activities that may imply in physical and emotional efforts, thus, inducing BP elevation. In addition, pre-exercise BP levels were taken around 2pm, while post-exercise BP was measured around 4-

Motriz, Rio Claro, v.19, n.2, p.252-260, abr./jun. 2013
$6 \mathrm{pm}$. It is known that BP increases during the afternoon, achieving a peak around $6 \mathrm{pm}$ (HERMIDA et al., 2007; PORTALUPPI; SMOLENSKY, 2007). Therefore, the increase in diastolic BP may reflect the BP circadian variation at this time of the day.

Heart rate increased until 6 hours after both resistance exercise sessions. These results are consistent with previous studies (DEVAN et al., 2005; HEFFERNAN et al., 2006; REZK et al., 2006) and they have been attributed to the increase in sympathetic activity and decrease in parasympathetic activity in the heart after exercise (REZK et al., 2006). Additionally, heart rate was higher in the 130 group than in the 190 group during the first hour of recovery. Although heart rate was monitored during the resistance exercise, these results probably reflect the higher heart rate values during exercise when shorter rest intervals were adopted. This hypothesis is supported by Ratames' study (RATAMESS et al., 2007), which showed higher heart rate values with shorter rest intervals between sets. However, despite the increase in heart rate at the first hour mark, the cardiovascular overload was similar between sessions during the awake period, indicating that this tachycardia is transient and does not persist for a long period.

We analyzed the effects of the inter-set rest interval length during resistance exercise on several variables obtained from ambulatory $\mathrm{BP}$ monitoring, and no differences were found between 130 and 190. A previous study (RATAMESS et al., 2007) observed that increases in the metabolic response last for only 30 minutes after resistance exercise with 30 seconds of rest interval. Furthermore, another study found that resistance exercise with 1 or 3 minutes of rest interval significantly decreased diastolic BP only in the first 30 and $15 \mathrm{~min}$, respectively (VELOSO et al., 2010). These results suggest that the cardiovascular responses to resistance exercise in healthy subjects do not persist until the subject is asleep.

The practical application of this study was that after a resistance exercise session with $50 \%$ of the 1-RM, heart rate responses are higher with a $30 \mathrm{sec}$ interval in comparison with a $90 \mathrm{sec}$ 
interval in the first hours of recovery. However, in the 24 hours after resistance exercise, cardiovascular responses are similar between the 130 and 190 groups. These results suggest that rest interval length does not affect the cardiovascular response after a low-intensity resistance exercise. Therefore, healthy individuals who do not have much time to perform the exercise session may adopt a shorter rest interval between sets, which will not increase postexercise cardiovascular overload. Future studies should address whether a similar response occurs in hypertensive subjects.

This study has limitations. The participants did not undergo a control session, and, therefore, it was, not possible to identify the extent of the cardiovascular responses after exercise. However, as the purpose of this study was to compare two resistance exercise protocols, the design adopted in this study was adequate to meet this goal. In the current study, the participants were young and healthy, limiting the generalization of the results for hypertensive participants. Finally, the resistance exercises were performed at $50 \%$ of the $1-\mathrm{RM}$, and the results may not be extrapolated for higher intensities.

In conclusion, a shorter rest interval between sets increases heart rate for 1 hour after exercise. However, this response is transient as the 24-hour cardiovascular responses were similar after resistance exercise performed with rest intervals of 30 and $90 \mathrm{sec}$.

\section{References}

AMERICAN COLLEGE OF SPORTS MEDICINE. American College of Sports Medicine position stand. Progression models in resistance training for healthy adults. Med Sci Sports Exerc, Michigan, v.41, n.3, p.687-708, 2009.

AMERICAN COLLEGE OF SPORTS MEDICINE. Diretrizes do ACSM. para os Testes de Esforço e sua Prescrição. Rio de Janeiro: Editora Guanabara Koogan. 2007

CASTINHEIRAS-NETO, A. G.; COSTA-FILHO, I. R.FARINATTI, P. T. [Cardiovascular responses to resistance exercise are affected by workload and intervals between sets]. Arq Bras Cardiol, São Paulo, v.95, n.4, p.493-501, 2010.
CLARKE, D. H. Adaptations in strength and muscular endurance resulting from exercise. Exerc Sport Sci Rev, Indianapolis, v.1, p.73-102, 1973.

DE SALLES, B. F.; MAIOR, A. S.; POLITO, M.; NOVAES, J.; ALEXANDER, J.; RHEA, M.SIMAO, $R$. Influence of rest interval lengths on hypotensive response after strength training sessions performed by older men. J Strength Cond Res, Philadelphia, v.24, n.11, p.3049-3054, 2010.

DEVAN, A. E.; ANTON, M. M.; COOK, J. N.; NEIDRE, D. B.; CORTEZ-COOPER, M. Y.TANAKA, $\mathrm{H}$. Acute effects of resistance exercise on arterial compliance. J Appl Physiol, Bethesda, v.98, n.6, p.2287-2291, 2005.

FORJAZ, C. L.; CARDOSO, C. G., JR.; REZK, C C.; SANTAELLA, D. F.TINUCCI, T. Postexercise hypotension and hemodynamics: the role of exercise intensity. J Sports Med Phys Fitness, Torino, v.44, n.1, p.54-62, 2004.

FORJAZ, C. L.; SANTAELLA, D. F.; REZENDE, L. O.; BARRETTO, A. C.NEGRAO, C. E. Effect of exercise duration on the magnitude and duration of post-exercise hypotension. Arq Bras Cardiol, São Paulo, v.70, n.2, p.99-104, 1998.

FORJAZ, M.; REZK, C. C.; SANTAELLA, D. F.; MARANHÃO, G. D. F. A.; SOUZA, M. O.; NUNES, N.; NERY, S.; BISQUOLO, V. A. F.; RONDON, M. U. P. B.; MION JUNIOR, D.NEGRÃO, C. E. Hipotensão pós-exercício: características, determinantes e mecanismos. Rev. Soc. Cardiol, São Paulo, v.10, p.16-24, 2000.

HEFFERNAN, K. S.; KELLY, E. E.; COLLIER, S. R.FERNHALL, B. Cardiac autonomic modulation during recovery from acute endurance versus resistance exercise. Eur J Cardiovasc Prev Rehabil, Berlin, v.13, n.1, p.80-86, 2006.

HERMIDA, R. C.; AYALA, D. E.; CALVO, C.; PORTALUPPI, F.SMOLENSKY, M. H. Chronotherapy of hypertension: administrationtime-dependent effects of treatment on the circadian pattern of blood pressure. Adv Drug Deliv Rev, Salt Lake City, v.59, n.9-10, p.923-939, 2007.

KRAEMER, W. J.RATAMESS, N. A. Hormonal responses and adaptations to resistance exercise and training. Sports Med, Auckland, v.35, n.4, p.339-361, 2005.

LAGALLY, K. M.; ROBERTSON, R. J.; GALLAGHER, K. I.; GOSS, F. L.; JAKICIC, J. M.; LEPHART, S. M.; MCCAW, S. T.GOODPASTER, B. Perceived exertion, electromyography, and blood lactate during acute bouts of resistance 
exercise. Med Sci Sports Exerc, Michigan, v.34, n.3, p.552-559, 2002.

LIZARDO, J. H.; SILVEIRA, E. A.; VASSALLO, D. V.OLIVEIRA, E. M. Post-resistance exercise hypotension in spontaneously hypertensive rats is mediated by nitric oxide. Clin Exp Pharmacol

Physiol, Oxford, v.35, n.7, p.782-787, 2008.

MACDONALD, J. R. Potential causes, mechanisms, and implications of post exercise hypotension. J Hum Hypertens, London, v.16, n.4, p.225-236, 2002.

MEDIANO, M. F. F.; PARAVIDINO, V.; SIMÃO, R.; PONTES, F. L.POLITO, M. D. Comportamento subagudo da pressão arterial após o treinamento de força em hipertensos controlados. Rev Bras Med Esporte, São Paulo, v.11, n.6, p.337-340, 2005.

MENÊSES, A. L.; FORJAZ, C. L. D. M.; SILVA, G. Q. D. M.; LIMA, A. H. R. D. A.; FARAH, B. Q.; FILHO, O. D. L. L.; LIMA, G. H. C. D.RITTI-DIAS, R. M. Post exercise cardiovascular effects of different resistance exercise protocols for trunk and upper limbs. Motriz, São Paulo, v.17, n.4, p.667-674, 2011.

PESCATELLO, L. S.; BAIROS, L.; VANHEEST, J. L.; MARESH, C. M.; RODRIGUEZ, N. R.; MOYNA, N. M.; DIPASQUALE, C.; COLLINS, V.; MECKES, C. L.; KRUEGER, L.THOMPSON, P. D. Postexercise hypotension differs between white and black women. Am Heart J, New York, v.145, n.2, p.364-370, 2003.

PESCATELLO, L. S.; GUIDRY, M. A.; BLANCHARD, B. E.; KERR, A.; TAYLOR, A. L.; JOHNSON, A. N.; MARESH, C. M.; RODRIGUEZ, N.THOMPSON, P. D. Exercise intensity alters postexercise hypotension. J Hypertens, London, v.22, n.10, p.1881-1888, 2004.

PINCIVERO, D. M.; LEPHART, S.

M.KARUNAKARA, R. G. Effects of rest interval on isokinetic strength and functional performance after short-term high intensity training. $\mathbf{B r} \mathbf{J}$ Sports Med, London, v.31, n.3, p.229-234, 1997.

POLITO, M. D.FARINATTI, P. T. The effects of muscle mass and number of sets during resistance exercise on postexercise hypotension. J Strength Cond Res, Philadelphia, v.23, n.8, p.2351-2357, 2009.

PORTALUPPI, F.SMOLENSKY, M. H. Circadians rhythms and enviromental determinants of blood pressure regulation in normal and hypertensive conditions. In: (Ed.). Blood Pressure Monitoring in Cardiovascular Medicine and Therapeutics. Totowa: H. Press, 2007. Circadians rhythms and enviromental determinants of blood pressure regulation in normal and hypertensive conditions, p.133-156

QUEIROZ, A. C.; GAGLIARDI, J. F.; FORJAZ, C. L.REZK, C. C. Clinic and ambulatory blood pressure responses after resistance exercise. $\mathbf{J}$ Strength Cond Res, Philadelphia, v.23, n.2, p.571-578, 2009.

RATAMESS, N. A.; FALVO, M. J.; MANGINE, G. T.; HOFFMAN, J. R.; FAIGENBAUM, A. D.KANG, $J$. The effect of rest interval length on metabolic responses to the bench press exercise. Eur $\mathbf{J}$ Appl Physiol, Basel, v.100, n.1, p.1-17, 2007.

REZK, C. C.; MARRACHE, R. C.; TINUCCI, T.; MION, D., JR.FORJAZ, C. L. Post-resistance exercise hypotension, hemodynamics, and heart rate variability: influence of exercise intensity. Eur J Appl Physiol, Basel, v.98, n.1, p.105-112, 2006.

SIMAO, R.; FLECK, S. J.; POLITO, M.; MONTEIRO, W.FARINATTI, P. Effects of resistance training intensity, volume, and session format on the postexercise hypotensive response. J Strength Cond Res, Philadelphia, v.19, n.4, p.853-858, 2005.

SOARES-CALDEIRA, L. F.; RITTI-DIAS, R. M.; OKUNO, N. M.; CYRINO, E. S.; GURJAO, A. L.PLOUTZ-SNYDER, L. L. Familiarization indexes in sessions of 1-RM tests in adult women. $\mathbf{J}$ Strength Cond Res, Philadelphia, v.23, n.7, p.2039-2045, 2009.

TAKARADA, Y.ISHII, N. Effects of low-intensity resistance exercise with short interset rest period on muscular function in middle-aged women. $\mathbf{J}$ Strength Cond Res, Philadelphia, v.16, n.1, p.123-128, 2002.

VELOSO, J.; POLITO, M. D.; RIERA, T.; CELES, R.; VIDAL, J. C.BOTTARO, M. [Effects of rest interval between exercise sets on blood pressure after resistance exercises]. Arq Bras Cardiol, São Paulo, v.94, n.4, p.512-518, 2010.

WALLACE, J. P.; BOGLE, P. G.; KING, B. A.; KRASNOFF, J. B.JASTREMSKI, C. A. The magnitude and duration of ambulatory blood pressure reduction following acute exercise. $\mathbf{J}$ Hum Hypertens, London, v.13, n.6, p.361-366, 1999.

WILLIAMS, M. A.; HASKELL, W. L.; ADES, P. A.; AMSTERDAM, E. A.; BITTNER, V.; FRANKLIN, B. A.; GULANICK, M.; LAING, S. T.STEWART, K. J. Resistance exercise in individuals with and without cardiovascular disease: 2007 update: a scientific statement from the American Heart Association Council on Clinical Cardiology and Council on Nutrition, Physical Activity, and 
Metabolism. Circulation, Boston, v.116, n.5, p.572-584, 2007.

This study was supported by Conselho Nacional de Desenvolvimento Científico e Tecnológico $(\mathrm{CNPq})$ and Programa de Fortalecimento Acadêmico da UPE (PFA - UPE).

This study was approved by the Institutional Review Board of the University of Pernambuco.

\section{Corresponding author:}

Raphael Ritti-Dias, PhD

School of Physical Education - University of Pernambuco

Rua Arnóbio Marques, 310 Santo Amaro

Recife PE Brazil

50100-130

Telephone: 558131833379

e-mail: raphaelritti@gmail.com

Recebido em: 5 de novembro de 2011.

Aceito em: 11 de março de 2013.

\section{cC) (†)}

Motriz. Revista de Educação Física. UNESP, Rio Claro, SP, Brasil - elSSN: 1980-6574 - está licenciada sob Creative Commons - Atribuição 3.0 